\title{
In situ electrochemical synthesis of graphene-poly(arginine) composite for p-nitrophenol monitoring
}

\author{
Yiwei Li ${ }^{\mathrm{a}, \mathrm{b}}$, Yaohong Ma ${ }^{\mathrm{a}, \mathrm{b}}$, Eric Lichtfouse ${ }^{\mathrm{e}, \mathrm{f}}$, Jin Song ${ }^{\mathrm{a}, \mathrm{b}}$, Rui Gong ${ }^{\mathrm{g}}$, Jinheng Zhang ${ }^{\mathrm{a}, \mathrm{b}}$, \\ Shuo Wang ${ }^{\text {a,b }}$, Leilei Xiao ${ }^{\text {a,c, d, },, 1}$ \\ ${ }^{a}$ Biology Institute, Qilu University of Technology (Shandong Academy of Sciences), Jinan 250103, PR China \\ ${ }^{\mathrm{b}}$ Shandong Provincial Key Laboratory of Biosensors, Jinan 250103, PR China \\ ${ }^{\mathrm{c}}$ Key Laboratory of Coastal Biology and Biological Resources Utilization, Yantai Institute of Coastal Zone Research, Chinese Academy of Sciences, Yantai 264003, PR \\ China \\ d CAS Key Laboratory of Coastal Environmental Processes and Ecological Remediation, Yantai Institute of Coastal Zone Research, Chinese Academy of Sciences, Yantai \\ 264003, PR China \\ ${ }^{\mathrm{e}}$ Aix-Marseille Univ, CNRS, IRD, INRA, Coll France, CEREGE, Avenue Louis Philibert, Aix en Provence 13100, France \\ ${ }^{\mathrm{f}}$ State Key Laboratory of Multiphase Flow in Power Engineering, Xi'an Jiaotong University, Xi'an, Shaanxi 710049, PR China \\ ${ }^{\mathrm{g}}$ National Laboratory of Biomacromolecules, CAS Center for Excellence in Biomacromolecules, Institute of Biophysics, Chinese Academy of Sciences, 15 Datun Road, \\ Chaoyang District, Beijing 100101, PR China
}

\section{A R T I C L E I N F O}

Editor: Dr. Rinklebe Jörg

\section{Keywords:}

$P$-nitrophenol

Graphene

Poly-arginine

Electrochemical analysis

Wastewater monitoring

\begin{abstract}
A B S T R A C T
Para-Nitrophenol ( $p$-nitrophenol) is a common industrial pollutant occurring widely in water bodies, yet actual monitoring methods are limited. Herein we proposed a fully electrochemically in situ synthesized graphenepolyarginine composite functionalized screen printed electrode, as a novel p-nitrophenol sensing platform. The electrode was characterized by morphologic, spectrometric and electrochemical techniques. $p$-nitrophenol in both pure aqueous solution and real water samples was tested. Results show a detection limit as low as the nanomolar level, and display a linear response and high selectivity in the range of $0.5-1250 \mu \mathrm{M}$. Molecular simulation reveals a detailed synergy between graphene and poly-arginine. The preferable orientation of nitrophenol molecules on the graphene interface in the presence of poly-arginine induces $\mathrm{H}$ - and ionic binding. This sensor is an ideal prototype for $p$-nitrophenol quantification in real waters.
\end{abstract}

\section{Introduction}

Nitrophenols, such as $p$-nitrophenol, is vastly used in pharmaceuticals, pesticides, dyes, explosives and petroleum industries (Wang et al., 2016; Kumar et al., 2017). In air, water and soil, p-nitrophenol is found with high chemical stability and reluctant biodegradability, which make its removal challengeable (Han et al., 2019). It is highly toxic and can cause irreversible damages to human liver and kidneys. Therefore, $p$-nitrophenol has been classified priority pollutant among top 114 organic pollutants by the US Environmental Protection Agency, with allowed limit of $0.43 \mu \mathrm{M}(60 \mathrm{ppb})$ in drinking water (Menazea and Mostafa, 2020; Chakraborty et al., 2021).

Common analysis of $p$-nitrophenol include spectrophotometry (Zhang and Wilson, 2008; Niazi and Yazdanipour, 2007), ultra-high-pressure liquid chromatography (Chung et al., 2012), electrophoresis (Guo et al., 2004), molecular recognition assay (Liu et al., 2019; Dai et al., 2020) and fluorescent assays (Dai et al., 2020; Bogireddy et al., 2020). Although these methods present some advantages, they are limited by the need for man-sized instruments, expenses, experienced operators and slowness. Alternatively, electrochemical methods feature outstanding performances such as high-sensitivity, fast response, low-cost, easy operation and instrumental miniaturization (Karaman et al., 2021a, 2021b; Xiao et al., 2018, 2020; Karimi-Maleh et al., 2021a, 2021b; Balasubramanian et al., 2019; Li et al., 2012). Electrochemical detectors of nitrophenols have been recently designed using various active materials as well as electro-analytical techniques, such as semiconductive metal composites (Zhang et al., 2018; Wang et al., 2019a, 2019b; Su et al., 2021), metal nanoparticles (Madhu et al., 2014; Chao et al., 2017), polymers (Zhu et al., 2020) and carbon nanoparticles (Karaman et al., 2021a, 2021b; Karimi-Maleh et al.,

\footnotetext{
* Correspondence to: Yantai Institute of Coastal Zone Research, Chinese Academy of Sciences, Yantai 264003, P.R. China.

E-mail address: 1lxiao@yic.ac.cn (L. Xiao).

1 Orcid: 0000-0002-8535-8073
} 
Table 1

Electrochemical biosensors for detection of $p$-nitrophenol.

\begin{tabular}{|c|c|c|c|c|c|}
\hline Electrode architecture & Electrochemical technology & Linear range $(\mu \mathrm{M})$ & Sensitivity $\left(\mu \mathrm{A} \mu \mathrm{M}^{-1} \mathrm{~cm}^{-2}\right)$ & LOD $(\mu \mathrm{M})$ & Ref. \\
\hline AgNWs-PANI/GCE & DPV & $0.6-32$ & - & 0.052 & Chao et al., 2017 \\
\hline Cu-curcumin/GCE & DPV & $0.1-1030$ & 1.57 & 68.2 & Dinesh and Saraswathi, 2017 \\
\hline $\mathrm{FeO}_{\mathrm{x}} / \mathrm{TiO}_{2} @ \mathrm{mc} / \mathrm{GCE}$ & Amperometry & $5-310$ & 3.89 & 0.183 & Wang et al., 2019a, 2019b \\
\hline AgPd@UiO-66- $\mathrm{NH}_{2} / \mathrm{GCE}$ & DPV & $100-370$ & 1259.1 & 32 & Hira et al., 2019 \\
\hline HA-NP/GCE & DPV & $1-300$ & - & 0.6 & Yin et al., 2010 \\
\hline $\mathrm{ZnCo}_{2} \mathrm{O}_{4} / \mathrm{GCE}$ & DPV & $1-4000$ & 0.318 & 0.3 & Zhang et al., 2018 \\
\hline \multirow[t]{2}{*}{ PANI-array@CNF/GCE } & DPV & $0.01-0.1$ & 1.09 & 0.0015 & Zhu et al., 2020 \\
\hline & & $0.1-100$ & 0.24 & & \\
\hline PEDOT-PSS/ITO & LSV & $0-80$ & 0.129 & 4.51 & Hryniewicz et al., 2018 \\
\hline GO/GCE & LSV & $0.1-120$ & - & 0.02 & \\
\hline GC/rGO-Ag & SWV & $0.01-0.1$ & 12.65 & 0.0012 & Ikhsan et al., 2016 \\
\hline rGO- $\beta$-CD-CS & DPV & $5-40$ & 0.38 & - & Li et al., 2017 \\
\hline SWCNT/GCE & DPV & $0.01-5.00$ & - & 2.5 & Yang, 2004 \\
\hline MWCNT/GCE & SWV & $1-30$ & - & 0.12 & Arvinte et al., 2011 \\
\hline $\mathrm{Mn}-\mathrm{Fe}_{3} \mathrm{O}_{4} / 3 \mathrm{D}-\mathrm{G}$ & DPV & $5-100$ & 0.646 & 0.019 & Su et al., 2021 \\
\hline $\mathrm{AC} / \mathrm{GCE}$ & DPV & $1-500$ & - & 0.16 & Madhu et al., 2014 \\
\hline \multirow[t]{3}{*}{ P(Arg)/eG/SPE } & SWV & $0.5-1250$ & 0.661 & 0.012 & This work \\
\hline & Amperometry (Ox) & $5-1250$ & 1.295 & 0.0024 & \\
\hline & Amperometry (Red) & $5-200$ & 0.793 & 0.0039 & \\
\hline
\end{tabular}

2021a, 2021b). In particular, carbon nanomaterials were successfully applied to the detection of both small compounds and bio-macromolecules (Luo et al., 2020; Shen et al., 2019; Sengupta et al., 2020). However, optimizing all specifications such as high sensitivity, low detection limit, wide linear response, easy handling and low cost is challenging, as depicted in a comparison of actual methods (Table 1).

Among carbon materials, graphene has unique properties including high electrical conductance, huge surface area and absorbability, excellent electro-catalytic activity and versatile surface chemistry, which makes graphene an ideal electrochemical sensing material for $p$ nitrophenol (Cinti and Arduini, 2017; Shari et al., 2019). Wiench et al. (2017) demonstrated that the hydrothermally reduced graphene oxide interface is an excellent p-nitrophenol electro-catalyst, and extraordinary sensing stability within $\mathrm{pH}$ 4.0-5.0 was achieved. Nevertheless, interface of raw graphene is not optimal for detection, thus requiring architecture engineering and design of graphene composites. Mono-dispersions prevent graphene from the loss of electrochemical activity caused by graphene sheet restacking, which limits the contact of the analyte with graphene active sites (Shang et al., 2008; Chen et al., 2012; Cheng et al., 2017). As a consequence, scientists have designed composites by grafting functional materials such as metal nanoparticles, metal compounds, polymers, carbons and peptides (Yang et al., 2008; Cuenya, 2013; Su et al., 2021). Manganese cobalt oxide was introduced into graphene oxide (GO) as a dispersant to acquire better dispersed GO micro-architecture for p-nitrophenol analysis. Results showed that the metal oxide-GO composite exhibited much better

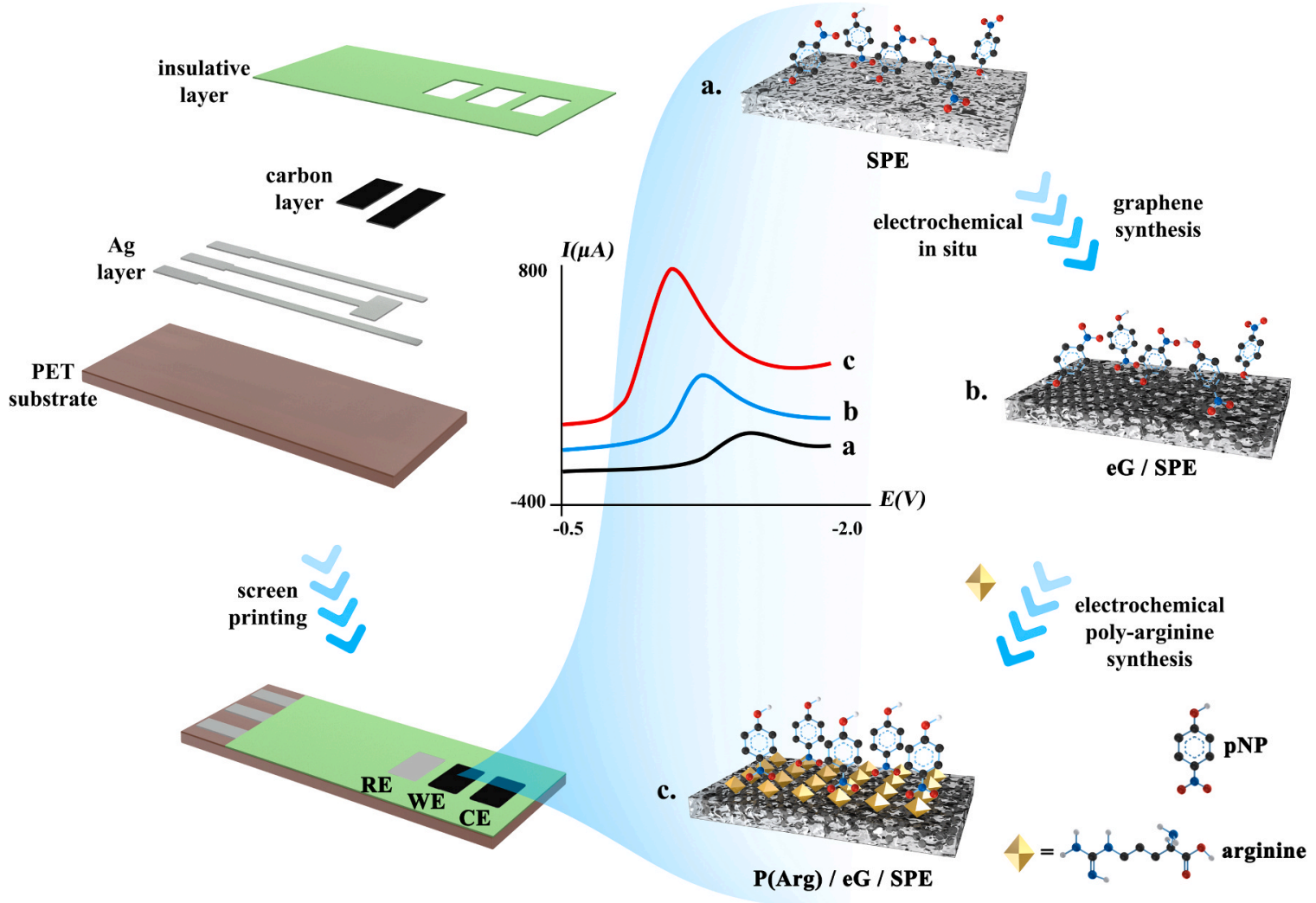

Scheme 1. Schematic presentation of the fabrication of the electrodes. 
electro-catalytic activity than the oxide and GO alone (Manjula and Chen, 2021).

Moreover, modifying graphene morphology by preparing graphene sponges and graphene-carbon hybrids can improve electro-catalytic properties (Asadian et al., 2017; Mohamed et al., 2018; Zhu et al., 2018). Su et al. (2021) fabricated a 3D graphene framework by using urushiol as an inter-layer spacer, and the pores within the framework were adapted to accommodate metal oxide catalyst. Sensor prepared thereof presented a limit of detection (LOD) to $p$-nitrophenol as low as $19 \mathrm{nM}$. In one study (Jaiswal and Tiwari, 2021), graphene framework was prepared by zinc ion chelating with a GO suspension. The coordination product formed 3D multi-layered structure to fully expose electro-catalytically active sites. The framework was highly sensitive to p-nitrophenol with LOD about $96 \mathrm{nM}$. Moreover, it can be used for distinguishing $p$-nitrophenol from $o$-nitrophenol. But those systems are costly and poorly stable in real conditions. In fact, we discovered that graphene can be easily synthesized in situ from any carbonaceous precursor by simple electrochemical methods (Li et al., 2019).

In the present work, we present a novel electrochemical sensor based on electrochemically in situ synthesized graphene interface anchored with poly-arginine (Sch. 1). This is the first $p$-nitrophenol sensor based on fully electrochemical synthesized nano-interface. The sensor shows high sensitivity for $p$-nitrophenol, low detection limit as well as wide dynamic range. Ideal repeatability, stability, anti-interference ability and real-sample applications are also observed. This sensor is suitable for multiple in-the-field scenario uses with satisfactory performances, cost-effectiveness, scalability and user-friendliness. Finally, we hypothesized that poly-arginine grafting improved $p$-nitrophenol detection by optimizing graphene surface morphology and favoring H-bond and ionic interactions between arginine and nitrophenols.

\section{Experimental section}

\subsection{Chemicals and reagents}

Monopotassium phosphate $\left(\mathrm{KH}_{2} \mathrm{PO}_{4}\right)$, potassium hydroxide $(\mathrm{KOH})$, hydrochloric acid $(\mathrm{HCl}, 37 \%)$, potassium ferricyanide $\left(\mathrm{K}_{3}\left[\mathrm{Fe}(\mathrm{CN})_{6}\right]\right.$, $99.5 \%)$, potassium ferricyanide trihydrate $\left(\mathrm{K}_{4}\left[\mathrm{Fe}(\mathrm{CN})_{6}\right] \cdot \mathrm{H}_{2} \mathrm{O}, 99.0 \%\right)$, phosphoric acid $\left(\mathrm{H}_{3} \mathrm{PO}_{4}, 99.0 \%\right)$, graphite powder (C, 800 mesh, $99.95 \%)$, sodium chloride $(\mathrm{NaCl}, 99.8 \%)$, potassium chloride $(\mathrm{NaCl}$, 99.8\%), calcium chloride $\left(\mathrm{CaCl}_{2}, 99.9 \%\right)$, potassium nitrate $\left(\mathrm{KNO}_{3}\right.$, 99.0\%), sodium sulfite $\left(\mathrm{Na}_{2} \mathrm{SO}_{3}, 99.0 \%\right)$, $p$-nitrophenol, $o$-nitrophenol (oNP, 98.0\%), m-nitrophenol (mNP, 99.0\%), $p$-aminophenol (pAP, 98.0\%), catechol (99.0\%), p-nitrobenzene (pNB, 99.0\%), phenol (99.0\%), hydroquinone (HQ, 99.5\%), $p$-hydroxybenzaldehyde (pHBA, 98.0\%), 2,3-dimethylphenol (DMP, 98.0\%), bisphenol A (BPA, 99.0\%) and sodium dodecylsulfonate (SDS, 98.0\%) were purchased from Aladdin Biochemical Technology Co., Ltd., Shanghai, used at achievement without further purification. Other reagents are of AR grade. Ultrapure water (resistivity: $\geq 18 \mathrm{M} \Omega \mathrm{cm}^{-1}$ ) was used for all experiments.

\subsection{Fabrication of screen printed electrode}

The procedure to prepare the screen printed electrode (denoted as SPE hereafter) is presented in Scheme 1. The electrode comprises a working electrode, a counter electrode and a pseudo-reference electrode. The patterns distribute into 4 layers, i.e., the polyethylene terephtalate (PET) substrate, the silver conductive/reference layer, the carbon working/counter layer and the insulative layer. All the patterns are transferred to nylon films (200 mesh) for preparing stencils by the local supplier. Silver ink (NT-ST60B, NanoTop Electronic Technology Ltd., PRC) was evenly spread onto the stencil and dragged the squeegee across the patterned area, leaving the ink transfer to the PET substrate. Curing the ink under $90^{\circ} \mathrm{C}$ for $90 \mathrm{~min}$ to obtain the conductive areas as well as the pseudo-reference electrode. Carbon ink (C2030519P4, Gwent Electronic Materials Ltd., UK) and insulative coating (CR-18T-
CK, Asahi Chemical Research Laboratory CO., LTD., Japan) were sequentially applied with the corresponding stencils and identical procedure to that of the silver ink, to form the working electrode, counter electrode and the insulative areas, respectively. Cut the whole printed board to obtain single SPE electrodes with each has a $2.0 \times 2.0 \mathrm{~mm}$ working electrode and counter electrode, and a $2.0 \times 1.0 \mathrm{~mm}$ reference electrode.

\subsection{Preparation of the electrodes $c G O / S P E, e G / S P E$ and $P(A r g) / e G / S P E$}

Preparation of chemically synthesized graphene oxide and the screen printed electrode modified thereof was modified from the literature (Marcano et al., 2010), and detailed in Supplementary Note 1, (denoted the electrode as cGO/SPE).

To prepare the electrochemically in situ synthesized graphene modified screen printed electrode (eG/SPE), bare screen printed electrode was immersed into $0.2 \mathrm{M} \mathrm{H}_{3} \mathrm{PO}_{4}$ solution contains $0.5 \mathrm{v} / \mathrm{v} \% \mathrm{SDS}$, $1.8 \mathrm{~V}$ direct current potential was imposed to the working electrode $v s$. an external $\mathrm{Ag} / \mathrm{AgCl}$ reference electrode for $200 \mathrm{~s}$. Then the electrode was fully rinsed with water and processed by cyclic voltammetry scans $\left(-2.0\right.$ to $0 \mathrm{~V}, 100 \mathrm{mV} / \mathrm{s}$ for 10 consecutive cycles) in $0.1 \mathrm{M} \mathrm{KNO}_{3}$ solution. After rinsing with water, the electrode was designated eG/SPE. The electrochemically in situ synthesized graphene-poly(arginine) modified screen printed electrode (P(Arg)/eG/SPE) was fabricated by immersing eG/SPE into $0.1 \mathrm{M}$ phosphate buffer solution ( $\mathrm{pH}$ 7.0) contains $20 \mathrm{mM} \mathrm{L-arginine,} \mathrm{perform} \mathrm{a} 10$ cycles cyclic voltammetry scans under $50 \mathrm{mV} \mathrm{s}^{-1}$ between the potential range of $-2.0-2.0 \mathrm{~V}$.

\subsection{Characterizations}

Scanning electronic microscope (SEM, Hitachi, X-650), Raman spectroscopy (JY Labram HR 800, $632.8 \mathrm{~nm}$ laser), X-ray photoelectron spectroscopy (XPS, ESCALAB 250 using Al Ko radiation source), and Fourier transform infrared spectroscopy (FTIR, Nicolet 6700 with a DTGS detector and Omnic 8.0 software, Thermo Fisher Scientific, USA) were used to characterize surface state of the electrodes include morphology, chemical composition, and their changes. Unless stated otherwise, voltammetric, amperometric, and electrochemical impedance spectroscopy (EIS) experiments were performed with the build-in three-electrode system of the SPE. All electrochemical experiments were carried out with the electrochemical workstation (CHI 760E, $\mathrm{CH}$ Instruments Inc., USA) equipped with a 5-mL homemade reactor under ambient condition.

\subsection{Molecular simulation}

The calculation is based on a grid-based molecular docking method that employs CHARMm. Random ligand conformations are generated from the initial ligand structure through high temperature molecular dynamics, followed by random rotations. The Calculate Energy (DFT) protocol was used to calculate the energy or optimize the geometry of a set of small molecules using the density functional quantum mechanics method. Finally, the theoretical computational modeling were presented.

\section{Results and discussion}

\subsection{Characterization of SPE, eG/SPE and $P(A r g) / e G / S P E$}

We analyzed electrodes including the bare screen printed electrode (SPE), the electrochemically in situ synthesized graphene modified screen printed electrode (eG/SPE) and the electrochemically in situ synthesized graphene-poly(arginine) modified screen printed electrode (P(Arg)/eG/SPE). Cyclic voltammetry was applied to perform the in situ electrochemical polymerization of arginine in $0.1 \mathrm{M}$ phosphate buffer solution $(\mathrm{pH}=7.0)$ in presence of $2.0 \mathrm{mM} \mathrm{L}$-arginine. $(-2.0$ to $2.0 \mathrm{~V}$, 

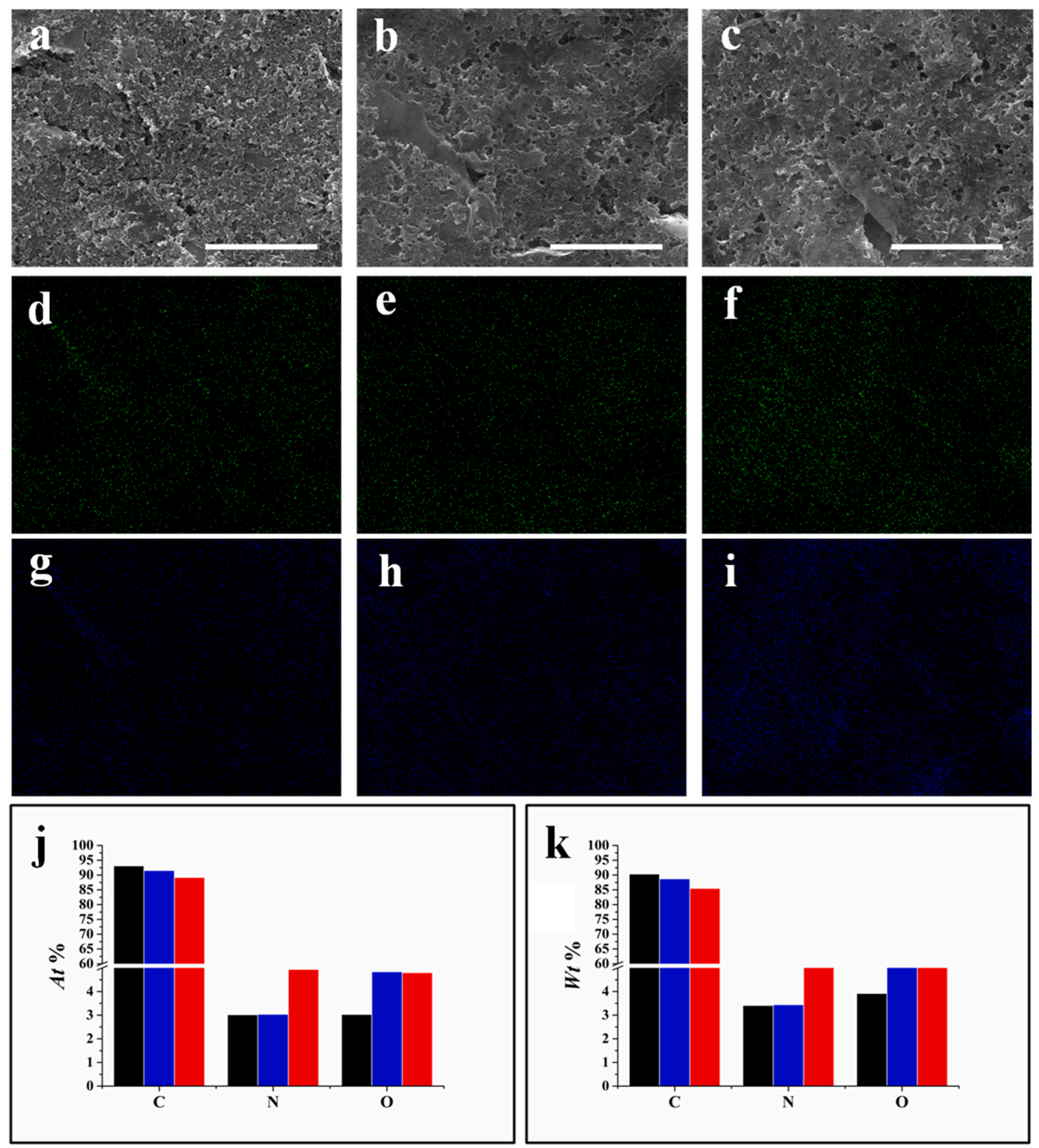

Fig. 1. Characterization of SPE, eG/SPE and P(Arg)/eG/SPE. Scanning electron microscopy of SPE (a), eG/SPE (b) and P(Arg)/eG/SPE (c). Energy disperse spectroscopy of $\mathrm{N}(\mathrm{d}, \mathrm{e}, \mathrm{f})$ and $\mathrm{O}(\mathrm{g}, \mathrm{h}, \mathrm{i})$, and the corresponding column graph showing the atomic percentages (j) and weight percentages (k) on SPE (black), eG/SPE (blue) and P(Arg)/eG/SPE (red). (For interpretation of the references to colour in this figure legend, the reader is referred to the web version of this article.)

$100 \mathrm{mV} \mathrm{s}^{-1}$ ). Ten consecutive cycles of the electro-deposition process of P(Arg) onto newly prepared eG/SPE was shown in Fig. S1. Results show that the electrolytic current became weak up cycle-wise with slower rates, approximating to a finally stable state. This indicates the accumulation of poly-arginine onto the eG/SPE surface with weak or none conductivity of acquired poly-arginine, according to previous studies (Behbahani et al., 2012; Ali et al., 2020).

The morphology of the three electrodes was analyzed by SEM (Fig. 1). The scattered graphite particles are clearly visible and show the surface state of the electrode (Fig. 1a). After the electrochemical processing, graphite particles are partially dissociated with some flat, edged plates (Fig. 1b). This morphology, generally observed in graphite contained electrodes under acoustic anodization conditions (Palanisamy et al., 2014; Niu et al., 2017; González-Sánchez et al., 2018), facilitates the in situ synthesis of a graphene oxide layer (Li et al., 2019).
EDS mapping results show the differences of $\mathrm{N}$ and $\mathrm{O}$ contents in the raw electrode, graphene oxide electrode and polyarginine-grafted graphene oxide electrode (Fig. 1j). The oxygen increase supports the formation of graphene oxides during anodization. Then, the increase of nitrogen agrees with the formation and attachment of polyarginine on the surface (Fig. 2).

FTIR results show that arginine has distinctive peaks at $1329 \mathrm{~cm}^{-1}$ and $1447 \mathrm{~cm}^{-1}$, corresponding to symmetric stretching of free carboxyls, whereas these peaks decrease in poly-arginine (Fig. 2a). Similarly, the peak of $\mathrm{C}-\mathrm{N}$ and $\mathrm{N}-\mathrm{H}$ stretching at $3348 \mathrm{~cm}^{-1}$ corresponding to free amino groups decreases in poly-arginine. The formation of amide bonds in polyarginine is supported by new peaks of $\mathrm{C}-\mathrm{N}$ and $\mathrm{N}-\mathrm{H}$ stretching at $1077 \mathrm{~cm}^{-1}, \mathrm{C}-\mathrm{N}$ stretching and $\mathrm{N}-\mathrm{H}$ bending at $1524 \mathrm{~cm}^{-1}$, and carbonyl stretching at $1644 \mathrm{~cm}^{-1}$. Overall, these data confirm arginine polymerization on the electrode surface (Zhang et al., 

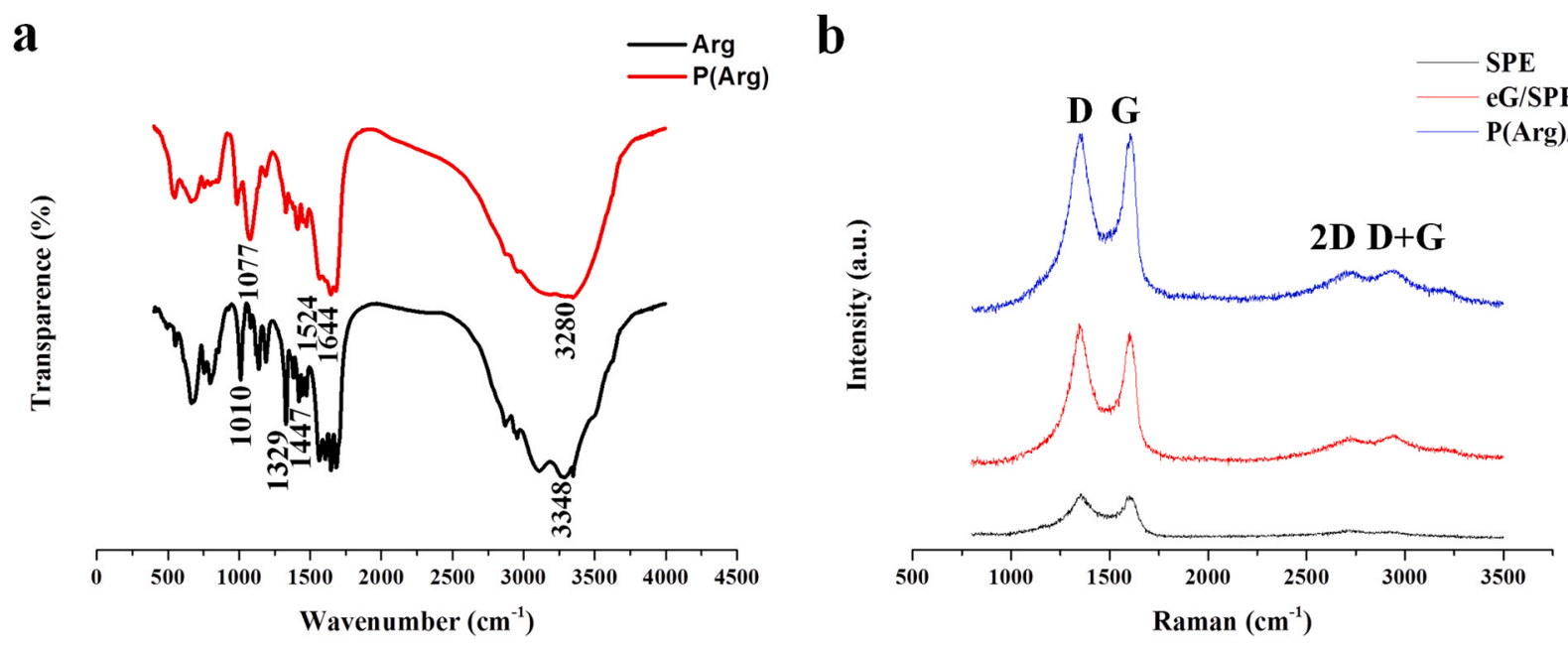

Fig. 2. FTIR (a) of Arg and P(Arg), and Raman spectra (b) of SPE, eG/SPE and P(Arg)/eG/SPE.

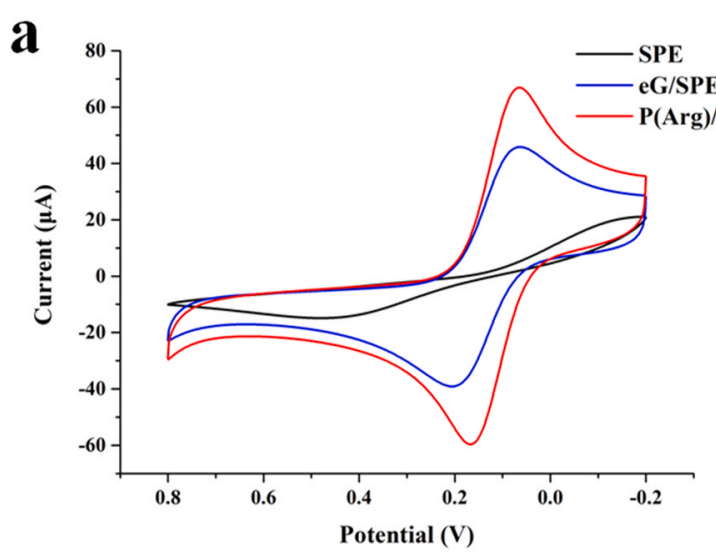

c

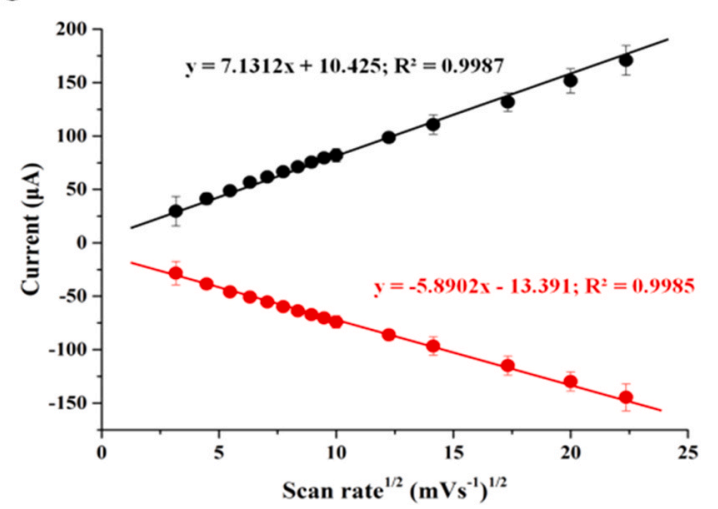

b

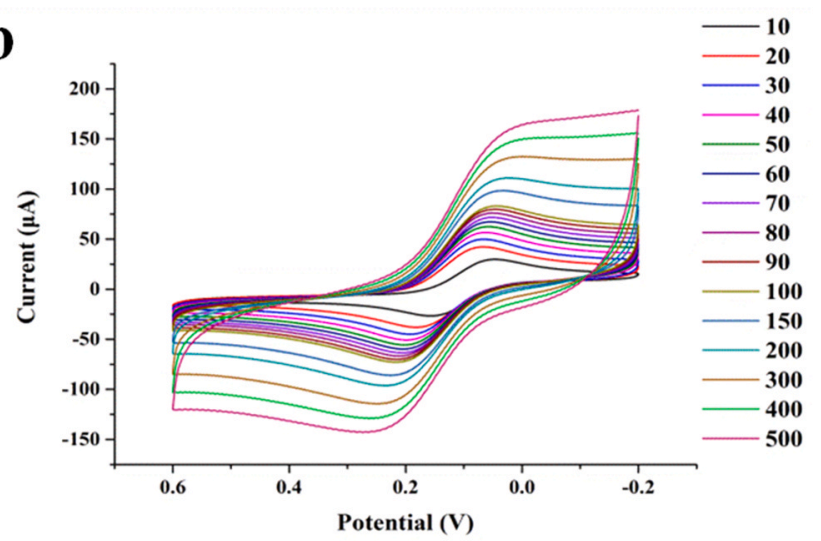

d

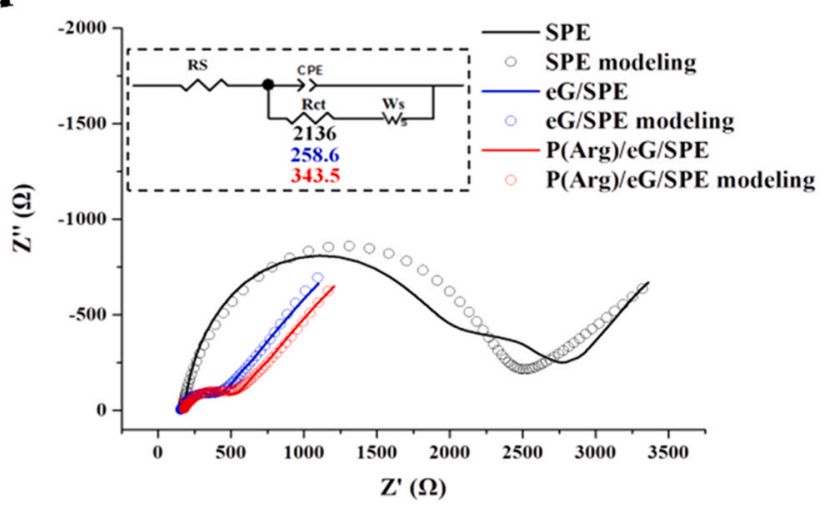

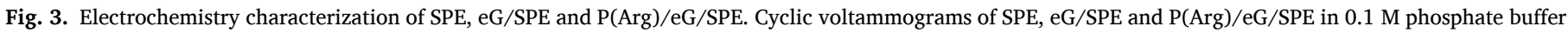

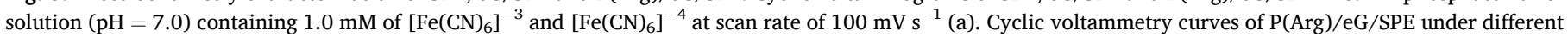

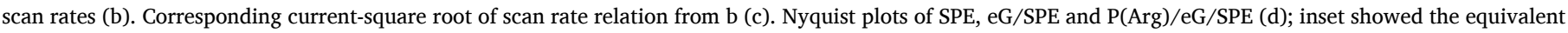
circuit from electrochemical impedance spectroscopy modeling (dotted curves) with the method and solution in Supplementary Note 2.

\section{2; Li et al., 2021).}

Raman spectra show two main peaks (Fig. 2b), D peak at $1323 \mathrm{~cm}^{-1}$ and the $\mathrm{G}$ peak at $1580 \mathrm{~cm}^{-1}$ representing in-plane vibrations of sp2 carbons and the intrinsic structural defects on graphene lattice, respectively (Ambrosi et al., 2014). The increase of the $D / G$ ratio from 0.955 in the raw electrode to 1.062 in the anodized electrode is explained by the rising number of carbon defects. The 2D band at $\sim 2700 \mathrm{~cm}^{-1}$ and $\mathrm{D}+\mathrm{G}$ band at $\sim 2910 \mathrm{~cm}^{-1}$ are suggesting the formation of a mono-layered graphenic structure, as observed previously (Li et al., 2019). The decrease of the D/G ratio from 1.062 in the anodized electrode to 0.998 in the poly-arginine grafted anodized electrode is explained by the growth of the poly-arginine layer (McColl et al., 2003).

XPS was applied to further identify the atomic changes of the electrodes. As is shown in Fig S2, C1s deconvolution spectrum of SPE shows peaks at $284.67 \mathrm{eV}, 285.2 \mathrm{eV}, 286.5 \mathrm{eV}$ and $288.8 \mathrm{eV}$, attributed to sp2 


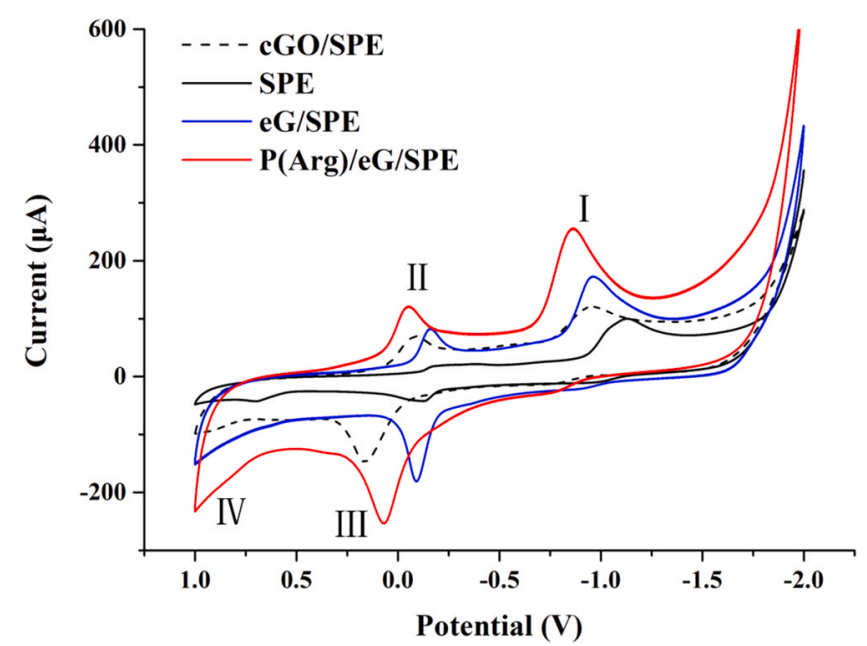

Fig. 4. Cyclic voltammograms of cGO/SPE, SPE, eG/SPE and P(Arg)/eG/SPE at scan rate of $100 \mathrm{mV} \mathrm{s}^{-1}$ in presence of $1.0 \mathrm{mM}$ p-nitrophenol.

carbons, sp3 carbons, $\mathrm{C}-\mathrm{O}$ and $\mathrm{C}=\mathrm{O} / \mathrm{COO}$ group, respectively. The data show the composition of graphite and the polymer binder contained in the carbon ink (Fig S2a). For eG/SPE, the ratio of sp2 to sp3 increased, indicating the in situ production of graphene on the electrode surface (Fig S2b). For P(Arg)/eG/SPE, a new peak at $285.9 \mathrm{eV}$ attributed to $\mathrm{C}-\mathrm{N}$ linkage is observed, indicating the formation of P(Arg) (Fig S2c) (Ayiania et al., 2020). This peak was also found in the monomeric arginine. By comparison, the $\mathrm{C}-\mathrm{NH}_{2}$ peak at $288.0 \mathrm{eV}$ largely depleted in polyarginine, as previous report (Zhang et al., 2014). Overall, these data confirm electrochemical polymerization of arginine on the electrode.

To further understand the properties of these electrodes, electrochemical behaviors were first studied by cyclic voltammetry method. As shown in Fig. 3a, a characteristic reversible peak pair can be observed, showing their electro-catalytic activity towards ferro/ferricyanide ions. But manifestly, SPE (black) exhibited the worst electrochemical performance with lowest peak currents $(I p a=43.0 \mu \mathrm{A})$, and a large peak potential difference $(\triangle E p)$ value, indicating a slow electrochemical kinetics. In comparison, eG/SPE markedly enhanced the performance. The Ipa enlarged to $329 \mu \mathrm{A}$ and the $\Delta E p$ value reduced to $\sim 135 \mathrm{mV}$. For $\mathrm{P}$ (Arg)/eG/SPE, Ipa further increased to $592.8 \mu \mathrm{A}$ and the $\Delta E p$ value decreased to $\sim 85 \mathrm{mV}$. These data directly displayed the highly electrocatalytic activity of P(Arg)/eG/SPE to the surface dependent electroactivity species. Further, Fig. $3 \mathrm{~b}$ and $\mathrm{c}$ provided the results with $\mathrm{P}$ (Arg)/eG/SPE to detect ferro/ferricyanide ions at different scan rates. Within the range of $10-500 \mathrm{mV} \mathrm{s}^{-1}$, good linear correlation was obtained between the peak currents and their corresponding square root of scan rates $\left(I p c=7.1312 c+10.425, \mathrm{R}^{2}=0.99 ;\right.$ Ip $a=-5.8902 \mathrm{c}$ $13.391, R^{2}=0.99$ ). This indicated the electrochemical reaction of the surface dependent species followed a diffusion controlled kinetics ( Li et al., 2018), which is advantageous to sensor applications for the target of the same category.

For all three electrodes in the high frequency range analyzed by electrochemical impedance spectroscopy (Fig. 3d), a semi-circular region always appeared and became the predominate variable, indicating that the electron transfer resistance, $R_{c t}$, is the main factor changed on a

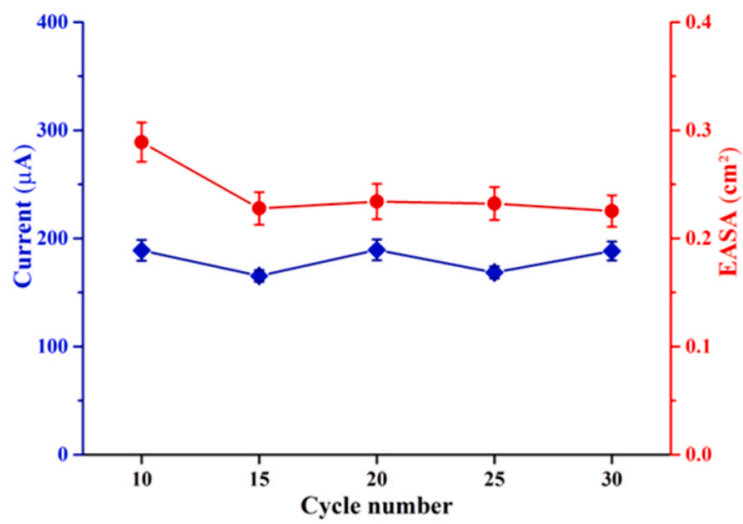

c

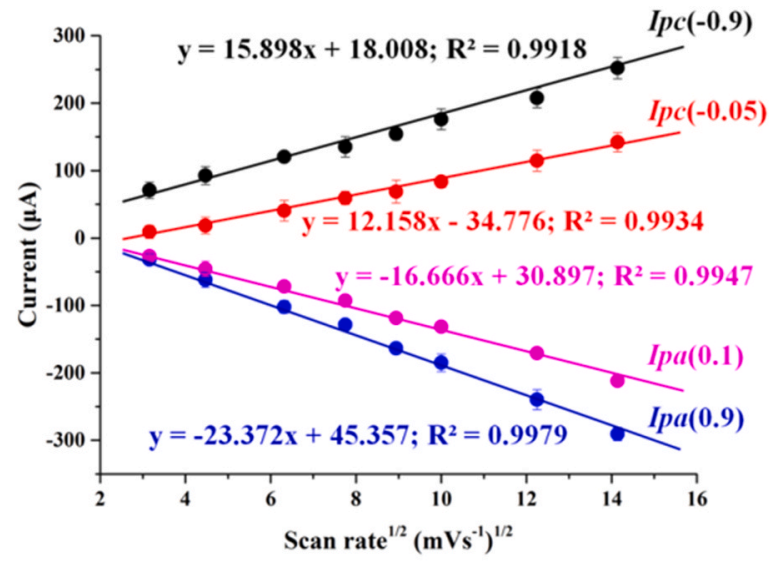

b

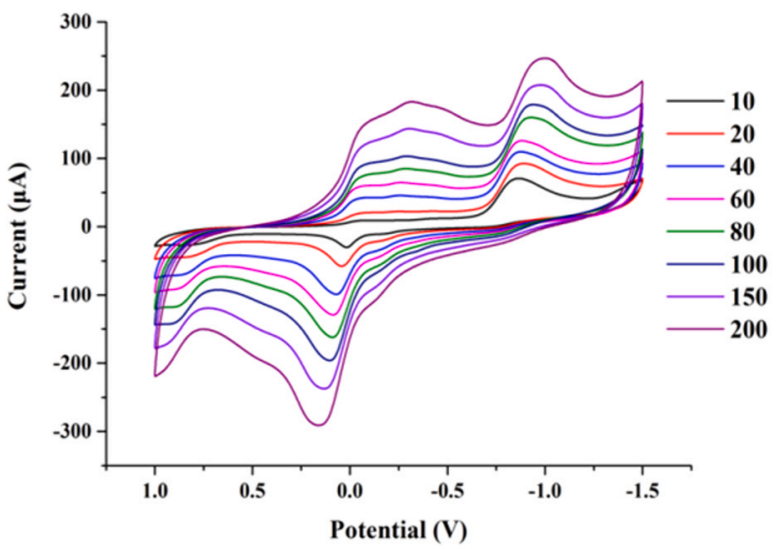

d

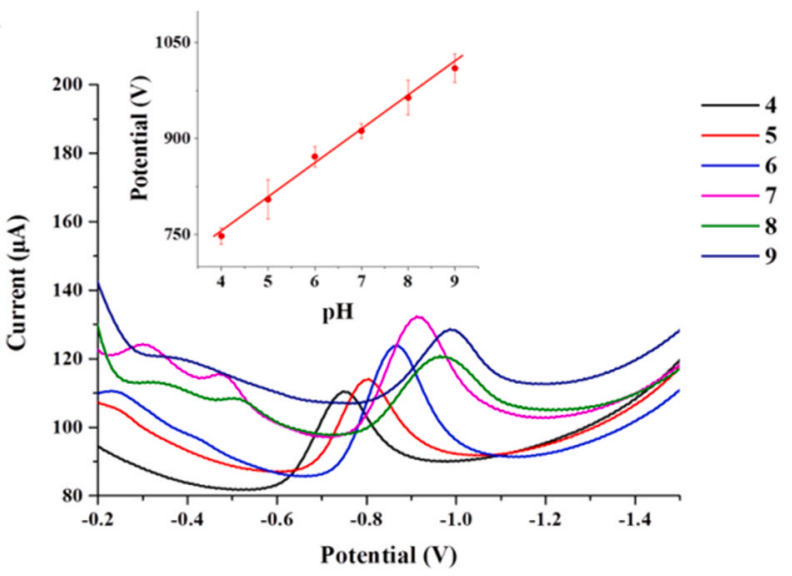

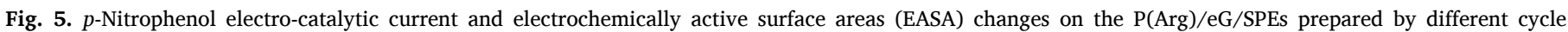

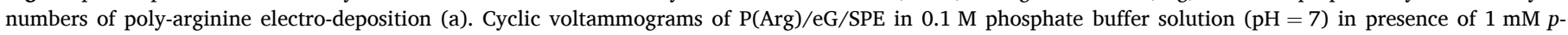

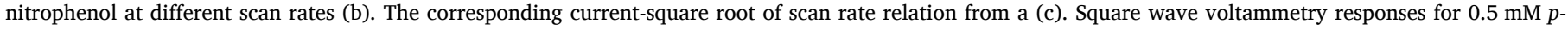
nitrophenol in $0.1 \mathrm{M}$ phosphate buffer solution of different $\mathrm{pH}$; the inset showing the relation between the peak potential and pH (d). 

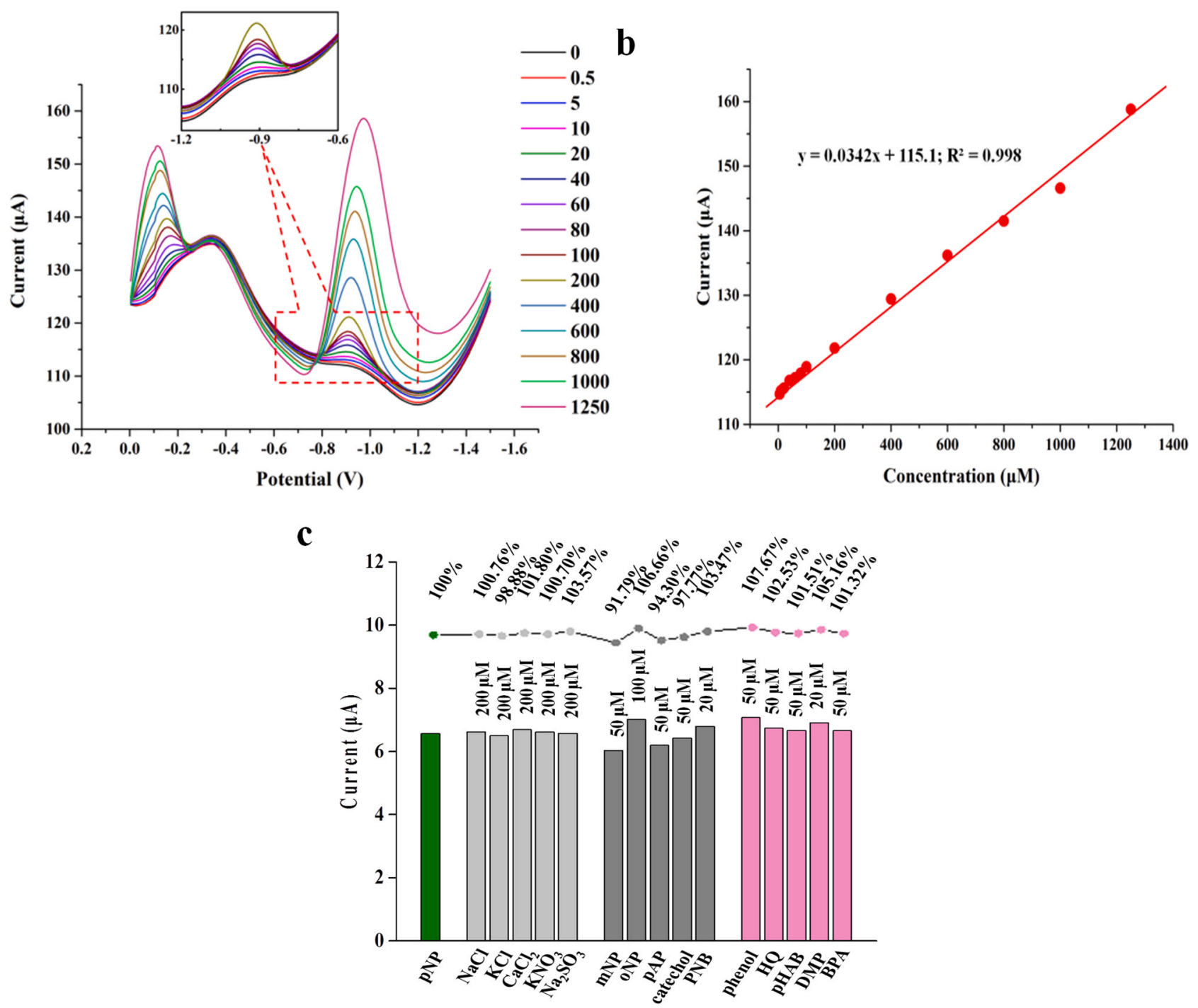

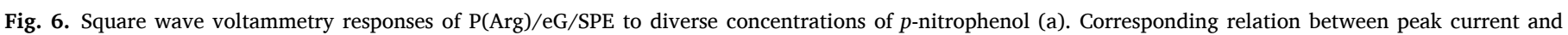
concentration (b). Selectivity of $\mathrm{P}(\mathrm{Arg}) / \mathrm{eG} / \mathrm{SPE}$ over the foremost possible interfering compounds (c).

the electrodes. By further modeling and calculation, the equivalent circuits were acquired (Fig. 3d, inset). $R_{c t}$ drastically declined from $2136 \Omega$ on SPE to $258.6 \Omega$ on eG/SPE, showing the high conductance of the in situ synthesized graphene layer. The $R_{c t}$ value of P(Arg)/eG/SPE, however, increased weakly back to $343.5 \Omega$, revealing the weak conductivity of poly-arginine. This is consistent with the cyclic voltammetry result aforementioned. Actually, the in situ synthesized graphene layer predominantly contributed to the electro-catalytic activity and the surface conductivity. P(Arg) mainly enhanced the electrode interface to exert higher electro-catalytic activity (Fig. 4).

\subsection{Electrochemical performances for p-nitrophenol detection}

We compared the electro-catalytic performance of bare screen printed electrode (SPE), the electrochemically in situ synthesized graphene modified screen printed electrode (eG/SPE) and the electrochemically in situ synthesized graphene-poly(arginine) modified screen printed electrode (P(Arg)/eG/SPE), along with the counterpart, chemically synthesized graphene oxide modified screen printed electrode (cGO/SPE) in the presence of nitrophenol (Fig. 4). Peak I at - $1200 \mathrm{mV}$ is the irreversible reduction of nitrophenol. The reversible peak II at $-200 \mathrm{mV}$ and peak III at $-170 \mathrm{mV}$ represent the reduction of $p$ hydroxylaminophenol and p-nitrosophenol (Renu et al., 2021; Huang et al., 2021). Peak IV at $750 \mathrm{mV}$ is attributed to the oxidation of the phenolic moiety of nitrophenol. Results show that the polyarginine-grafted electrode displays the best performance with the highest currents, versus the oxidized electrode and the classical graphene oxide electrode, cGO/SPE. The raw electrode showed the weakest performance. The best potential for nitrophenol monitoring is at peak I.

\subsection{Effect of electro-deposition of poly-arginine, $\mathrm{pH}$ and scan rate on the electro-catalytic performance}

We studied the effect of the electrochemically active surface area, $\mathrm{pH}$ and scan rate on the performance of the polyarginine-grafted graphene electrode. Areas were changed by varying cyclovoltametric deposition cycles. We observed little variation of current intensity from 10 to 30 cycles, whereas electrochemically active surface areas decreased above 10 cycles (Fig. 5a). Similar phenomena were observed in the previous reports (Zhang et al., 2012; Li et al., 2021). So 10 cycles were adopted for further experiments. The electrochemical behaviour of the electrode in response to nitrophenol at different scan rates is shown in Fig. 5b and linear correlations are observed at peak I, II, III and IV (Fig. 5c). Findings show that the nitrophenol transformation is controlled by diffusion in the $10-200 \mathrm{mV} \mathrm{s}^{-1}$ range. The study of the effect of $\mathrm{pH}$ shows that the polyarginine electrode reached optimum current at $\mathrm{pH} 6$ and $\mathrm{pH}$ is well 
Table 2

Recoveries of $p$-nitrophenol in real-world samples $(n=3)$.

\begin{tabular}{lcrrl}
\hline Sample & $\begin{array}{l}\text { Standard addition } \\
(\mu \mathrm{M})\end{array}$ & $\begin{array}{l}\text { Fund } \\
(\mu \mathrm{M})\end{array}$ & $\begin{array}{l}\text { Recovery } \\
\%\end{array}$ & $\begin{array}{l}\text { SD } \\
\%\end{array}$ \\
\hline Industrial & 5 & 5.02 & 100.4 & 1.7 \\
wastewater & 25 & 24.59 & 98.4 & 1.2 \\
& 50 & 49.63 & 99.3 & 0.6 \\
Lab. wastewater & 5 & 4.88 & 97.6 & 1.4 \\
& 25 & 25.20 & 100.8 & 1.0 \\
River water & 50 & 50.14 & 100.3 & 0.7 \\
& 5 & 4.77 & 95.4 & 2.3 \\
& 25 & 24.81 & 99.2 & 1.4 \\
& 50 & 50.30 & 100.6 & 1.1 \\
\hline
\end{tabular}

correlated with potential according to $E p=52.229 \mathrm{pH}+545.65$ with $\mathrm{r}^{2}$ of 0.99 (Fig. 5d). This finding indicates that the electro-reduction of nitrophenol is a proton-coupled process with equimolar transfer number of $\mathrm{H}^{+}$and $\mathrm{e}^{-}$in a wide acidity range (Zhu et al., 2020).

\subsection{Voltammetric performances for sensitive p-nitrophenol detection}

Square wave voltammetry was applied to examine P(Arg)/eG/SPE. Testing parameters are shown in Supplementary Note 3. Fig. 6a showed that $\mathrm{P}(\mathrm{Arg}) / \mathrm{eG} / \mathrm{SPE}$ presented clear responses to $p$-nitrophenol concentration within range of $0-1250 \mu \mathrm{M}$. A good linear relationship was obtained between the Ipc values and the concentration of $p$-nitrophenol with the range of $0.5-1250 \mu \mathrm{M}$ (Fig. 6b). The regressive equation was Ipc $(\mu \mathrm{A})=0.0342 C(\mu \mathrm{M})+115.1\left(\mathrm{R}^{2}=0.99\right)$. The sensitivity of the sensor was calculated to be $0.66 \mu \mathrm{A}^{-1} \mathrm{~cm}^{-2}$ by the Eq. (1) (Chakraborty et al., 2021),
Sensitivity $=k / A$

where, $k$ designates the slop of the above regressive equation, $A$ is the electrochemically active surface area calculated in Supplementary Note 4, with the calculated $A=0.0514 \mathrm{~cm}^{2}$.

The limit of detection (LOD) was determined as $12 \mathrm{nM}$, calculated following the criterion of $\mathrm{S} / \mathrm{N}=3$ (Su et al., 2021), using Eq. (2),

$\mathrm{LOD}=3 N / k$

$N=$ standard deviation value of the response; $k=$ calibration curve slop.

Comparing with the previous results in Table 1, it can be seen the $\mathrm{P}$ (Arg)/eG/SPE fabricated in this research has excellent quantification performances as a $p$-nitrophenol electrochemical sensor.

Reproducibility of this sensor was evaluated by testing the square wave voltammetry responses with $5 \mathrm{P}(\mathrm{Arg}) / \mathrm{eG} / \mathrm{SPE}$ sheets prepared independently in $0.1 \mathrm{M}$ phosphate buffer solution $(\mathrm{pH}=7)$ containing $1.0 \mu \mathrm{M} p$-nitrophenol. The relative standard deviation (RSD) was found to be $5.2 \%$. RDS was $1.2 \%$ for the repeatability analysis, which was tested by performing 5 independent measures in the same solution with each in triplet (Supplementary Fig S3a). For stability investigation, 3 newly prepared $\mathrm{P}(\mathrm{Arg}) / \mathrm{eG} / \mathrm{SPE}$ sheets were stored under ambient condition and tested in the same solution every $24 \mathrm{~h}$ for 7 days. Over $90 \%$ signal retention rate was gotten within the 7-day experiment (Fig S3b and $\mathrm{c}$ ).

In the real world, some possible interferents may cause detection distortion to the sensor (Su et al., 2021; Renu et al., 2021). We therefore chose some most likely interferent to investigate the sensor's selectivity. To investigate the selectivity of the sensor, we used 3 groups of possible
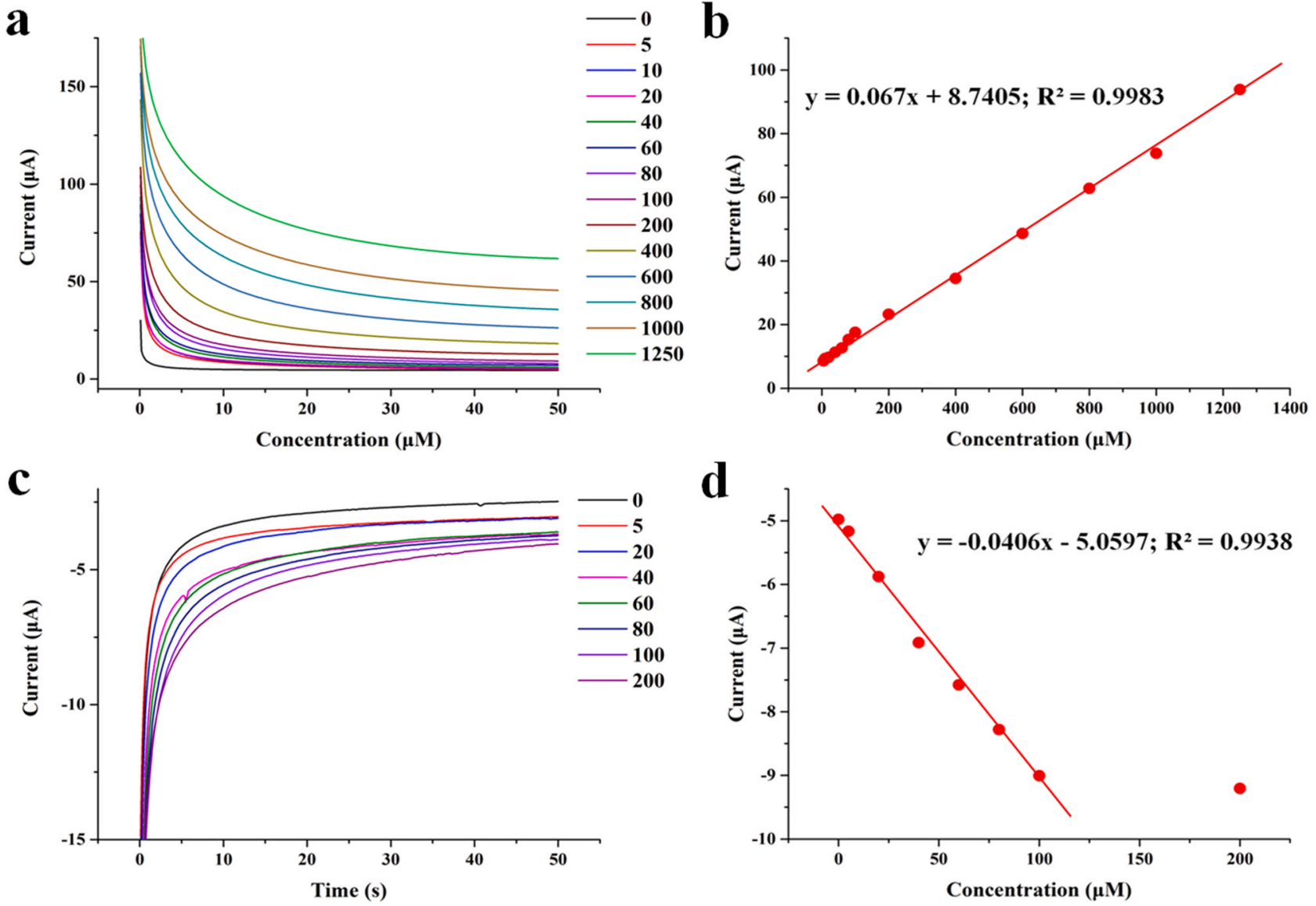

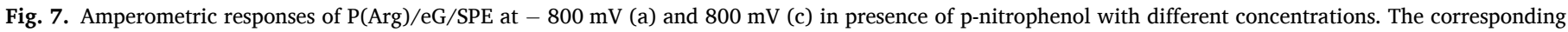
regressive relation between current and $p$-nitrophenol concentration sampled at 3rd second. 


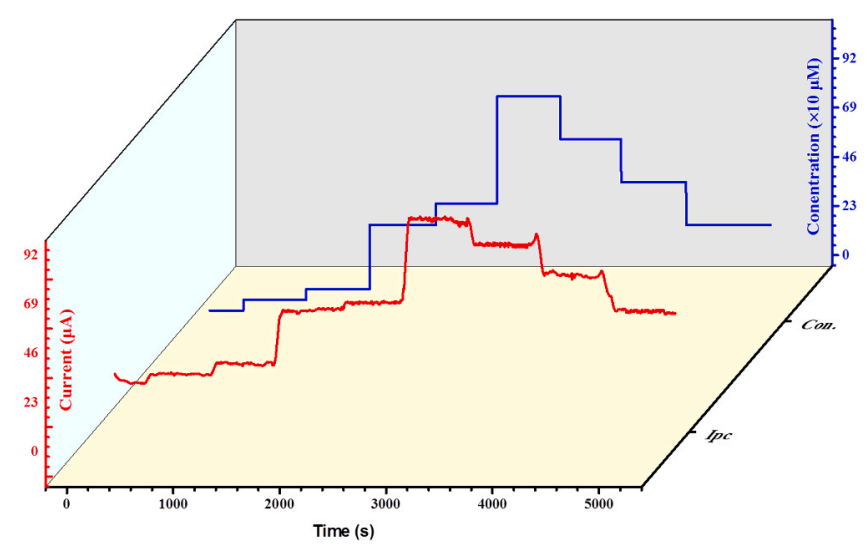

Fig. 8. Amperometric responses (red) of $\mathrm{P}(\mathrm{Arg}) / \mathrm{eG} / \mathrm{SPE}$ to the pulsing concentrations of $p$-nitrophenol (blue). $(\times 10 \mu \mathrm{m}$ means to multiply ten to the corresponding number on the Y-axis, in the unit of $\mu \mathrm{M}$ )

interferent to perform the anti-interference test (Fig. 6c). In the first group, common co-existing ions include $\mathrm{Na}^{+}, \mathrm{K}^{+}, \mathrm{Ca}^{2+}, \mathrm{Cl}^{-}, \mathrm{NO}_{3}^{-}, \mathrm{SO}_{3}^{2-}$ with almost no influence to the sensing signal of $p$-nitrophenol. In the 2nd group, homologs and isomers of $p$-nitrophenol are studied with signal recovery ratios ranging from $91.79 \%$ to $106.66 \%$. The 3 rd was group composed of phenols which are also homologous to $p$-nitrophenol. Slight signal deviation from $101.32 \%$ to $107.67 \%$ is detected. For all experiments, the signal recovery ratios are within range of 91.79-107.67\%, with the most cases less than 5.0\%. Among these, isomer $o$-nitophenol and phenol caused the most prominent interference due to high homology of the structure to $p$-nitrophenol, yet their influence is acceptable to real applications.

Overall, results show good selectivity and anti-interference of the sensor. Moreover, real-world samples were used to perform the standard addition tests. As the results shown in Table 2, in all cases the error produced in the complex samples were less than $3 \%$, which further demonstrated a worthy applicability. Collectively, $\mathrm{P}(\mathrm{Arg}) / \mathrm{eG} / \mathrm{SPE}$ is an ideal sensor for portable $p$-nitrophenol detection with high sensitivity, wide quantification range and good reliability.

\subsection{Amperometry for long-term p-nitrophenol monitoring}

Many cases require long-term, consecutive quantifications of $p$ nitrophenol level other than the need for one-off detection. Considering this, the ability of the sensor to continual $p$-nitrophenol monitoring was investigated. The $i$ - $t$ curves recorded in $0.1 \mathrm{M}$ phosphate buffer solution $(\mathrm{pH}=7.0)$ in presence of $p$-nitrophenol with various concentrations (Fig. 7). Data in Fig. 7a and c were obtained using peak I and peak IV with the working potential of $-800 \mathrm{mV}$ and $800 \mathrm{mV}$, respectively. Regressive curves were obtained by sampling the current values at the 3rd second of each curve (Fig. $7 \mathrm{~b}$ and d). The regressive equations were gotten as follow: $I p c(\mu \mathrm{A})=0.067 C(\mu \mathrm{M})+8.7405\left(\mathrm{R}^{2}=0.99\right)$ and $I p a$ $(\mu \mathrm{A})=-0.041 C(\mu \mathrm{M})-5.0597\left(\mathrm{R}^{2}=0.99\right)$. The corresponding linear concentration ranges were $5-1250 \mu \mathrm{M}$ and $5-200 \mu \mathrm{M}$. Limit of detections were 2.4 and $3.9 \mathrm{nM}$, and sensitivities were 1.30 and $0.79 \mu \mathrm{A} \mu \mathrm{M}^{-1} \mathrm{~cm}^{-2}$. It is noticeable that for measuring higher concentration gradient $p$-nitrophenol samples under $800 \mathrm{mV}$, the catalytic current Ipa no longer increased or even weakened (data not shown). Electro-oxidation of p-nitrophenol may lead to in situ selfpolymerization, along with the irreversible adsorption of the oxidation product (Chen et al., 2008; Karabiberoğlu et al., 2019). The great surface fouling could largely passivate the sensor. Therefore, the reduction mode seemed to be preferable for the long-term monitoring.

A long-term consecutive monitoring of varied concentration of $p$ nitrophenol in phosphate buffer solution base is shown in Fig. 8. As the concentration of $p$-nitrophenol changed, the reductive current intensity presented a swift response. Even when $p$-nitrophenol concentration dropped to lower level, the sensor responded quickly with a in-step signal, indicating that this electrode was fouling-free and adaptive for consecutive monitoring.

\subsection{Molecular modeling}

Theoretical computational modeling was performed to study the interactions of p-nitrophenol with the $\mathrm{P}(\mathrm{Arg}) / \mathrm{eG} / \mathrm{SPE}$. According to the potential binding energy $\left(\Delta E_{A B}\right)$ predictions, two models were considered. The first one illustrated the arrangement of a $p$-nitrophenol molecule freely onto a graphene sheet. It was modeled with an in-plane defect which is common in electro-catalytic analyses (Liu et al., 2018; Wang et al., 2019a, 2019b). As shown in Fig. 9a, p-nitrophenol nearly parallelly attached to the graphene plane with the closest inter-molecular distance of $3.51 \AA$ (at the phenol moiety of p-nitrophenol), which is mainly induced by strongly non-specific adsorption. This is the reason why only limited performance gain harvested and the electrode fouling is severe on bare graphene interfaces.

In comparison, the existence of poly-arginine makes p-nitrophenol molecule re-orientate on graphene interface trough comprehensive effect from H-bonding, ionic attraction and hydrophobic force (Fig. 9b). In this second model, $p$-nitrophenol is tightly and vertically located at the detect of graphene plane with their distance reduced to $\sim 2.25 \AA$,
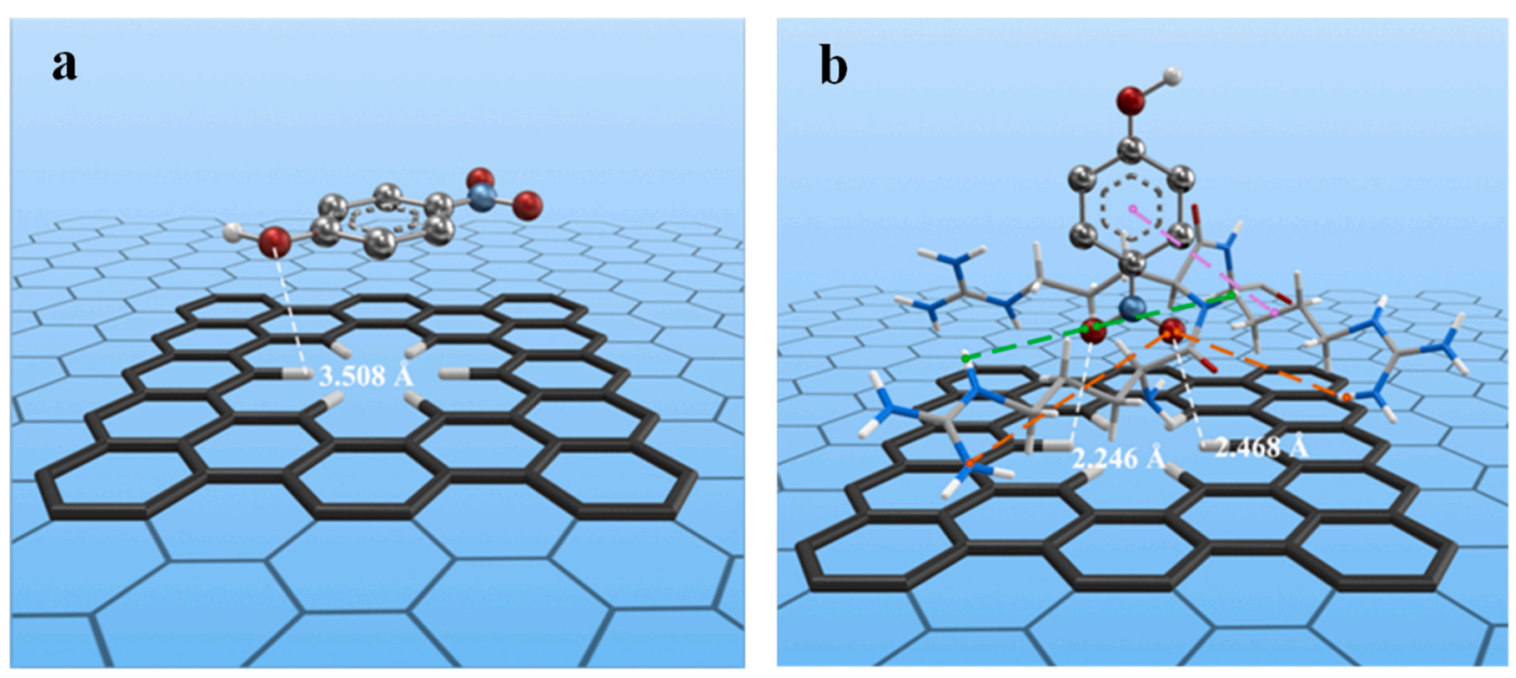

Fig. 9. Possible optimized configuration of $p$-nitrophenol-P(Arg)-graphene interactions (b) and that without $\mathrm{P}(\mathrm{Arg})$ (a) visualized by Rosetta package. 
revealed by density function theory calculation result. More importantly, poly-arginine benefit to drawing $-\mathrm{NO}_{2}$ moiety of $p$-nitrophenol towards the defect - the electrocatalytically active site on graphene plane. Consequently, $\mathrm{P}(\mathrm{Arg})$ assist preferable orientation of $p$-nitrophenol onto the sensing interface and present a synergy with in situ synthesized graphene to endow P(Arg)/eG/SPE with fast electrochemical kinetics. This verifies the vital importance of delicate molecular design of sensing interface to create optimized chemical microenvironment.

\section{Conclusion}

A fully electrochemically synthesized graphene screen printed electrode interface with poly-arginine anchored was successfully designed and applied for $p$-nitrophenol sensing. Using voltammetric technology, $\mathrm{P}$ (Arg)/eG/SPE fulfilled high sensitive $p$-nitrophenol detection with limit of detection as low as $12 \mathrm{nM}$. Moreover, a wide range quantification of $0.5-1250 \mu \mathrm{M}$ was fitted. By adapting amperometric method, highly sensitive and long-term consecutive $p$-nitrophenol level monitoring can be realized, with the limit of detection of $2.4 \mathrm{nM}$ and linear concentration range of $5-1250 \mu \mathrm{M}$. Specially, it is revealed by density function theory calculation that poly-arginine facilitates $p$-nitrophenol molecules to preferably orientate onto the graphene interface with fast electrochemical kinetics. Considering the very low cost of screen printed electrode fabrication, this sensor is an ideal prototype for the next generation versatile $p$-nitrophenol electrochemical sensing devices.

\section{CRediT authorship contribution statement}

Y.L. and L.X. designed the research. Y.L. J.Z. and S.W. conceptualized and performed the experiments. Y. L. and Y. M. contributed reagents, materials and analysis tools. Y. L., Y. M., J.S., L.X., and E.L. analyzed the data. R. G. performed the molecular simulation calculation. Y. L., J.S., L. $\mathrm{X}$. and E.L. wrote and revised the manuscript. All the authors discussed the results and commented on the manuscript.

\section{Declaration of Competing Interest}

The authors declare that they have no known competing financial interests or personal relationships that could have appeared to influence the work reported in this paper.

\section{Acknowledgements}

This research was financially supported by Youth Innovation Promotion Association, CAS (2021213) and the National Natural Science Foundation of China (no. 42077025).

\section{Appendix A. Supporting information}

Supplementary data associated with this article can be found in the online version at doi:10.1016/j.jhazmat.2021.126718.

\section{References}

Arvinte, A., Mahosenaho, M., Pinteala, M., Sesay, A.M., Virtanen, V., 2011.

Electrochemical oxidation of p-nitrophenol using graphene-modified electrodes, and a comparison to the performance of MWNT-based electrodes. Microchim. Acta 174, 337-343.

Ambrosi, A., Chua, C.K., Bonanni, A., Pumera, M., 2014. Electrochemistry of graphene and related materials. Chem. Rev. 114, 7150-7188.

Asadian, E., Shahrokhian, S., Zad, A.I., Ghorbani-Bidkorbeh, F., 2017. Glassy carbon electrode modified with 3D graphene-carbon nanotube network for sensitive electrochemical determination of methotrexate. Sens. Actuator B Chem. 239, 617-627.

Ayiania, M., Smith, M., Hensley, A.J., Scudiero, L., McEwen, J.S., Garcia-Perez, M., 2020 Deconvoluting the XPS spectra for nitrogen-doped chars: an analysis from first principles. Carbon 162, 528-544.
Ali, M.R., Bacchu, M.S., Daizy, M., Tarafder, C., Hossain, M.S., Rahman, M.M., Khan, M. Z.H., 2020. A highly sensitive poly-arginine based MIP as an electrochemical sensor for selective detection of dimetridazole. Anal. Chim. Acta 1121, 11-16.

Balasubramanian, P., Balamurugana, T.S.T., Chen, S.M., Chen, T.W., 2019. Simplistic synthesis of ultrafine $\mathrm{CoMnO}_{3}$ nanosheets: an excellent electrocatalyst for highly sensitive detection of toxic 4-nitrophenol in environmental water samples. J. Hazard. Mater. 361, 123-133.

Behbahani, M., Taghizadeh, M., Bagheri, A., Hosseini, H., Salarian, M., Tootoonchi, A., 2012. A nanostructured ion-imprinted polymer for the selective extraction and preconcentration of ultra-trace quantities of nickel ions. Microchim. Acta 178, $429-437$.

Bogireddy, N.K.R., Silva, R.C., Valenzuela, M.A., Agarwal, V., 2020. 4-nitrophenol optical sensing with N doped oxidized carbon dots. J. Hazard. Mater. 386, 121643.

Chakraborty, U., Bhanjana, G., Kannu, Kaur, N., Sharma, R., Kaur, G., Kaushik, A., Chaudhary, G.R., 2021. Microwave-assisted assembly of $\mathrm{Ag}_{2} \mathrm{O}-\mathrm{ZnO}$ composite nanocones for electrochemical detection of 4-Nitrophenol and assessment of their photocatalytic activity towards degradation of 4-Nitrophenol and Methylene blue dye. J. Hazard. Mater. 416, 125771.

Chung, R.J., Leong, M.I., Huang, S.D., 2012. Determination of nitrophenols using ultrahigh pressure liquid chromatography and a new manual shaking-enhanced, ultrasound-assisted emulsification microextraction method based on solidification of a floating organic droplet. J. Chromatogr. A 1246, 55-61.

Chao, Z., Govindaraju, S., Giribabu, K., Huh, Y.S., Yun, K., 2017. AgNWs-PANI nanocomposite based electrochemical sensor for detection of 4-nitrophenol. Sens. Actuator B Chem. 252, 616-623.

Chen, L.Y., Konishi, H., Fehrenbacher, A., Ma, C., Xu, J.Q., Choi, H., Xu, H.F., Pfefferkorn, F.E., Li, X.C., 2012. Novel nanoprocessing route for bulk graphene nanoplatelets reinforced metal matrix nanocomposites. Scr. Mater. 67 (1), 29-32.

Cheng, M.M., Zhang, X., Wang, M.X., Huang, H.Y., Ma, J.J., 2017. A facile electrochemical sensor based on well-dispersed graphene-molybdenum disulfide modified electrode for highly sensitive detection of dopamine. J. Electroanal. Chem. 786 (1), 1-7.

Cuenya, B.R., 2013. Metal nanoparticle catalysts beginning to shape-up. Acc. Chem. Res. 46, 1682-1691.

Cinti, S., Arduini, F., 2017. Graphene-based screen-printed electrochemical (bio)sensors and their applications: efforts and criticisms. Biosens. Bioelectron. 89, 107-122.

Chen, C., Sun, C., Gao, Y., 2008. Electrosynthesis of a net-like microstructured poly (paminophenol) film possessing electrochemical properties in a wide $\mathrm{pH}$ range. J. Macromol. Sci. A 45 (12), 972-979.

Dai, H., Deng, Z., Zeng, Y., Zhang, J., Yang, Y., Ma, Q., Hu, W., Guo, L., Li, L., Wan, S., Liu, H., 2020. Highly sensitive determination of 4-nitrophenol with coumarin-based fluorescent molecularly imprinted poly (ionic liquid). J. Hazard. Mater. 398, 122854.

Dinesh, B., Saraswathi, R., 2017. Electrochemical synthesis of nanostructured coppercurcumin complex and its electrocatalytic application towards reduction of 4 nitrophenol. Sens. Actuator B Chem. 253, 502-512.

Guo, X.F., Wang, Z.H., Zhou, S.P., 2004. The separation and determination of nitrophenol isomers by high-performance capillary zone electrophoresis. Talanta 64, 135-139.

González-Sánchez, M.I., Gómez-Monedero, B., Agrisuelas, J., Iniesta, J., Valero, E., 2018. Highly activated screen-printed carbon electrodes by electrochemical treatment with hydrogen peroxide. Electrochem. Commun. 91, 36-40.

Han, L., Liu, S.G., Liang, J.Y., Ju, Y.J., Li, N.B., Luo, H.Q., 2019. pH-mediated reversible fluorescence nanoswitch based on inner filter effect induced fluorescence quenching for selective and visual detection of 4-nitrophenol. J. Hazard. Mater. 362, 45-52.

Hira, S.A., Nallal, M., Park, K.H., 2019. Fabrication of PdAg nanoparticle infused metalorganic framework for electrochemical and solution-chemical reduction and detection of toxic 4-nitrophenol. Sens. Actuators B Chem. 298, 126861.

Hryniewicz, B.M., Orth, E.S., Vidotti, M., 2018. Enzymeless PEDOT-based electrochemical sensor for the detection of nitrophenols and organophosphates. Sens. Actuator B Chem. 257, 570-578.

Huang, R.M., Liao, D., Liu, Z.H., Yu, J.G., Jiang, X.Y., 2021. Electrostatically assembling $2 \mathrm{D}$ hierarchical $\mathrm{Nb}_{2} \mathrm{CTx}$ and ZIFs-derivatives into Zn-Co-NC nanocage for the electrochemical detection of 4-nitrophenol. Sens. Actuators B Chem. 338, 129828.

Ikhsan, N.I., Rameshkumar, P., Huang, N.M., 2016. Controlled synthesis of reduced graphene oxide supported silver nanoparticles for selective and sensitive electrochemical detection of 4-nitrophenol. Electrochim. Acta 192, 392-399.

Jaiswal, N., Tiwari, I., 2021. Self-assembled benzoic acid functionalized graphene oxide sheets with zinc (II) ions: graphene oxide framework; novel material for environmental sensing application. Synth. Met. 276, 116754.

Kumar, D.R., Kesavana, S., Baynosa, M.L., Shima, J.J., 2017. 3,5-Diamino-1,2,4triazole@electrochemically reduced graphene oxide film modified electrode for the electrochemical determination of 4-nitrophenol. Electrochim. Acta 246, 1131-1140.

Karabiberoğlu, Ş.U., Koçak, Ç.C., Dursun, Z., 2019. Electrochemical determination of dicofol at nickel nanowire modified poly (p-aminophenol) film electrode. Electroanal 31 (7), 1304-1310.

Karaman, C., Karaman, O., Atar, N., Yola, M.L., 2021a. Electrochemical immunosensor development based on core-shell high-crystalline graphitic carbon nitride@carbon dots and $\mathrm{Cd} 0.5 \mathrm{Zn} 0.5 \mathrm{~S} / \mathrm{d}-\mathrm{Ti}_{3} \mathrm{C}_{2} \mathrm{Tx}$ MXene composite for heart-type fatty acid-binding protein detection. Microchim. Acta 188, 182.

Karaman, C., Karaman, O., Atar, N., Yola, M.L., 2021b. Tailoring of cobalt phosphide anchored nitrogen and sulfur co-doped three dimensional graphene hybrid: boosted electrocatalytic performance towards hydrogen evolution reaction. Electrochim. Acta $380,138262$.

Karimi-Maleh, H., Yalo, M.L., Atar, N., Orooji, Y., Karimi, F., Kumar, P.S., Rouhi, J., Baghayeri, M., 2021a. A novel detection method for organophosphorus insecticide 
fenamiphos: molecularly imprinted electrochemical sensor based on core-shell $\mathrm{Co}_{3} \mathrm{O}_{4} @$ MOF-74 nanocomposite. J. Colloid Interface Sci. 592, 174-185.

Karimi-Maleh, H., Alizadeh, M., Orooji, Y., Karimi, F., Baghayeri, M., Rouhi, J., Tajik, S., Beitollahi, H., Agarwal, S., Gupta, V.K., Rajendran, S., Rostamnia, S., Fu, L., SaberiMovahed, F., Malekmohammadi, S., 2021b. Guanine-based DNA biosensor amplified with Pt/SWCNTs nanocomposite as analytical tool for nanomolar determination of daunorubicin as an anticancer drug: a docking/experimental investigation. Ind. Eng. Chem. Res. 60 (2), 816-823.

Li, J., Kuang, D., Feng, Y., Zhang, F., Xu, Z., Liu, M., 2012. A graphene oxidebasedelectrochemical sensor for sensitive determination of 4-nitrophenol. J. Hazard. Mater. 201, 250-259.

Li, C.K., Wu, Z.L., Yang, H., Deng, L., Chen, X.Q., 2017. Reduced graphene oxidecyclodextrin-chitosan electrochemical sensor: effective and simultaneous determination of o and p-nitrophenols. Sens. Actuator B Chem. 251, 446-454.

Li, J., Xiao, L., Zheng, S., Zhang, Y., Luo, M., Tong, C., Xu, H., Tan, Y., Liu, J., Wang, O., Liu, F., 2018. A new insight into the strategy for methane production affected by conductive carbon cloth in wetland soil: beneficial to acetoclastic methanogenesis instead of $\mathrm{CO}_{2}$ reduction. Sci. Total Environ. 643, 1024-1030.

Li, W., Diao, K., Qiu, D., Zeng, Y., Tang, K., Zhu, Y., Sheng, Y., Wen, Y., Li, M., 2021. A highly-sensitive and selective antibody-like sensor based on molecularly imprinted poly(L-arginine) on COOH-MWCNTs for electrochemical recognition and detection of deoxynivalenol. Food Chem. 350, 129229.

Li, Y.W., Zhou, J., Song, J., Liang, X.S., Zhang, Z.P., Men, D., Wang, D.B., Zhang, X.E., 2019. Chemical nature of electrochemical activation of carbon electrodes. Biosens. Bioelectron. 144, 111534.

Liu, W., Li, P., Wang, W., Zhu, D., Chen, Y., Peng, S., Paek, E., Mitlin, D., 2018. Directional flow-aided sonochemistry yields graphene with tunable defects to provide fundamental insight on sodium metal plating behavior. ACS Nano 12 (12), 12255-12268.

Liu, Y., Liu, Y., Liu, Z., Du, F., Qin, G., Li, G., Hu, X., Xu, Z., Cai, Z., 2019. Supramolecularly imprinted polymeric solid phase microextraction coatings for synergetic recognition nitrophenols and bisphenol A. J. Hazard. Mater. 368, 358-364.

Luo, S.X.L., Lin, C.J., Ku, K.H., Yoshinaga, K., Swager, T.M., 2020. Pentiptycene polymer/single-walled carbon nanotube complexes: applications in benzene, toluene, and o-xylene detection. ACS Nano 14 (6), 7297-7307.

Menazea, A.A., Mostafa, A.M., 2020. Ag doped $\mathrm{CuO}$ thin film prepared via pulsed laser deposition for 4-nitrophenol degradation. J. Environ. Chem. Eng. 8, 104104.

Madhu, R., Karuppiah, C., Chen, S.M., Veerakumar, P., Liu, S.B., 2014. Electrochemical detection of 4-nitrophenol based on biomass derived activated carbons. Anal. Methods 6, 5274-5280.

Mohamed, M.A., El-Gendy, D.M., Ahmed, N., Banks, C.E., Allam, N.K., 2018. 3D spongy graphene-modified screen-printed sensors for the voltammetric determination of the narcotic drug codeine. Biosens. Bioelectron. 101, 90-95.

Marcano, D.C., Kosynkin, D.V., Berlin, J.M., Sinitskii, A., Sun, Z., Slesarev, A., Alemany, L.B., Lu, W., Tour, J.M., 2010. Improved synthesis of graphene oxide. ACS Nano 4 (8), 4806-4814.

Manjula, N., Chen, S.M., 2021. Simple strategy synthesis of manganese cobalt oxide anchored on graphene oxide composite as an efficient electrocatalyst for hazardous 4-nitrophenol detection in toxic tannery waste. Microchem. J. 168, 106514.

McColl, I.H., Blanch, E.W., Gill, A.C., Rhie, A.G.O., Ritchie, M.A., Hecht, L., Nielsen, K., Barron, L.D., 2003. A new perspective on $\beta$-sheet structures using vibrational Raman optical activity: from poly(l-lysine) to the prion protein. J. Am. Chem. Soc. 125 (33), 10019-10026.

Niazi, A., Yazdanipour, A., 2007. Spectrophotometric simultaneous determination ofnitrophenol isomers by orthogonal signal correction and partial least squares. J. Hazard. Mater. 146, 421-427.

Niu, X., Shi, L., Li, X., Pan, J., Gu, R., Zhao, H., Qiu, F., Yan, Y., Lan, M., 2017. Simple anodization of home-made screen-printed carbon electrodes makes significant activity enhancement for hydrogen evolution: the synergistic effect of surface functional groups, defect sites, and hydrophilicity. Electrochim. Acta 235, 64-71.

Palanisamy, S., Karuppiah, C., Chen, S.M., Periakaruppan, P., 2014. Highly sensitive and selective amperometric nitrite sensor based on electrochemically activated graphite modified screen printed carbon electrode. J. Electroanal. Chem. 727, 34-38.

Renu, Komal, Kaur, R., Kaur, J., Jyoti, Kumar, V., Tikoo, K.B., Rana, S., Kaushik, A., Singhal, S., 2021. Unfolding the electrocatalytic efficacy of highly conducting
$\mathrm{NiFe}_{2} \mathrm{O}_{4}$-rGO nanocomposites on the road to rapid and sensitive detection of hazardous p-Nitrophenol. J. Electroanal. Chem. 887, 115161.

Sengupta, P., Pramanik, K., Datta, P., Sarkar, P., 2020. Chemically modified carbon nitride-chitin-acetic acid hybrid as a metal-free bifunctional nanozyme cascade of glucose oxidase-peroxidase for "click off" colorimetric detection of peroxide and glucose. Biosens. Bioelectron. 154, 112072.

Shang, N.G., Papakonstantinou, P., McMullan, M., Chu, M., Stamboulis, A., Potenza, A., Dhesi, S.S., Marchetto, H., 2008. Catalyst-free efficient growth, orientation and biosensing properties of multilayer graphene nanoflake films with sharp edge planes. Adv. Funct. Mater. 18, 3506-3514.

Shari, M., Avadi, M.R., Attar, F., Dashtestani, F., Ghorchian, H., Rezayat, S.M., Saboury, A.A., Falahati, M., 2019. Cancer diagnosis using nanomaterials based electrochemical nanobiosensors. Biosens. Bioelectron. 126, 773-784.

Shen, Y., Tran, T.T., Modha, S., Tsutsui, H., 2019. A Mulchandani. A paper-based chemiresistive biosensor employing single-walled carbon nanotubes for low-cost, point-of-care detection. Biosens. Bioelectron. 130, 367-373.

Su, Y., Zheng, X., Cheng, H., Rao, M., Chen, K., Xia, J., Lin, L., Zhu, H., 2021. Mn-Fe $\mathrm{O}_{4}$ nanoparticles anchored on the urushiol functionalized 3D-graphene for the electrochemical detection of 4-nitrophenol. J. Hazard. Mater. 409, 124926.

Wang, Y., Xie, Y., Sun, H., Xiao, J., Cao, H., Wang, S., 2016. Hierarchical shapecontrolledmixed-valence calcium manganites for catalytic ozonation of aqueousphenolic compounds. Catal. Sci. Technol. 6, 2918-2929.

Wang, M.H., Liu, Y.K., Yang, L.Y., Tian, K., He, L.H., Zhang, Z.H., Jia, Q.J., Song, Y.P., Fang, S.M., 2019a. Bimetallic metal-organic framework derived $\mathrm{FeO}_{\mathrm{x}} / \mathrm{TiO}_{2}$ embedded in mesoporous carbon nanocomposite for the sensitive electrochemical detection of 4-nitrophenol. Sens. Actuator B Chem. 281, 1063-1072.

Wang, P., Zhang, D., Tangc, H., Lia, H., Pan, B., 2019b. New insights on the understanding of the high adsorption of bisphenol compounds on reduced graphene oxide at high $\mathrm{pH}$ values via charge assisted hydrogen bond. J. Hazard. Mater. 371, 513-520.

Wiench, P., Grzyb, B., González, Z., Menéndez, R., Handke, B., Gryglewicz, G., 2017. pH robust electrochemical detection of 4-nitrophenol on a reduced graphene oxide modified glassy carbon electrode. J. Electroanal. Chem. 787, 80-87.

Xiao, L., Liu, F., Liu, J., Li, J., Zhang, Y., Yu, J., Wang, O., 2018. Nano- $\mathrm{Fe}_{3} \mathrm{O}_{4}$ particles accelerating electromethanogenesis on an hour-long timescale in wetland soil. Environ. Sci. Nano 5, 436-445.

Xiao, L., Zheng, S., Lichtfouse, E., Luo, M., Tan, Y., Liu, F., 2020. Carbon nanotubes accelerate acetoclastic methanogenesis: From pure cultures to anaerobic soils. Soil Biol. Biochem. 150, 111924.

Yang, C., 2004. Electrochemical determination of 4-Nitrophenol using a single-wall carbon nanotube film-coated glassy carbon electrode. Microchim. Acta 148, 87-92.

Yin, H., Zhou, Y., Ai, S., Liu, X., Zhu, L., Lu, L., 2010. Electrochemical oxidative determination of 4-nitrophenol based on a glassy carbon electrode modified with a hydroxyapatite nanopowder. Microchim. Acta 169, 87-92.

Yang, J.J., Pickett, M.D., Li, X., Ohlberg, D.A.A., Stewart, D.R., Williams, R.S., 2008. Memristive switching mechanism for metal/oxide/metal nanodevices. Nat. Nanotechnol. 3, 429-433.

Zhang, F., Wang, Z., Zhang, Y., Zheng, Z., Wang, C., Du, Y., Ye, W., 2012. Simultaneous electrochemical determination of uric acid, xanthine and hypoxanthine based on poly(l-arginine)/graphene composite film modified electrode. Talanta 93, 320-325.

Zhang, W., Wilson, C.R., 2008. Spectrophotometric simultaneous determination ofnitrophenol isomers by orthogonal signal correction and partial least squares. Talanta 74, 1400-1407.

Zhang, J.J., Cui, S.Q., Ding, Y.P., Yang, X.X., Guo, K., Zhao, J.T., 2018. Two-dimensional mesoporous $\mathrm{ZnCo}_{2} \mathrm{O}_{4}$ nanosheets as a novel electrocatalyst for detection of onitrophenol and p-nitrophenol. Biosens. Bioelectron. 112, 177-185.

Zhu, G., Tang, Q., Huang, M., Yang, J., Xu, R., Liu, J., 2020. Polyaniline nanoconical array on carbon nanofiber for supersensitive determination of nitrophenol. Sens. Actuators B Chem. 320, 128593.

Zhu, G.B., Sun, H., Zou, B., Liu, Z.J., Sun, N., Yi, Y.H., Wong, K., 2018. Electrochemical sensing of 4-nitrochlorobenzene based on carbon nanohorns/graphene oxide nanohybrids. Biosens. Bioelectron. 106, 136-141.

Zhang, Y., Li, Y., Zhang, P., 2014. De novo growth of poly (amidoamine) dendrimers on the surface of multi-walled carbon nanotubes. J. Mater. Sci. 49 (9), 3469-3477. 